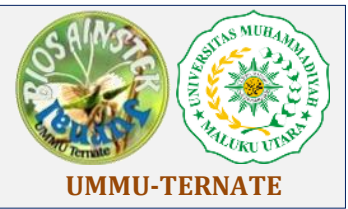

\title{
Analisis Pemanfaatan Pelayanan Kesehatan Masyarakat Kelurahan Rum di Wilayah Kerja Puskesmas Rum Balibunga Kota Tidore Kepulauan
}

\author{
Risaldi Abas $^{1}$, Didik Kurniawan ${ }^{\circledR}$ dan Eri Marwati ${ }^{2}$ \\ ${ }^{1}$ Fakultas Ilmu Kesehatan, Universitas Muhammadiyah Maluku Utara, Ternate, Indonesia \\ 2 Staf Pengajar Fakultas Ilmu Kesehatan, Universitas Muhammadiyah Maluku Utara. Ternate. Indonesia, \\ Email : kurniwandhy9@gmail.com; erimarwati77@gmail.com, \\ $\bigotimes_{\text {Korespondensi : Didik Kurniawan, Universitas Muhammadiyah Maluku Utara, Ternate, Indonesia, }}$
Email : kurniwandhy9@gmail.com
}

\section{ABSTRAK.}

Pemanfaatan pelayanan kesehatan merupakan faktor penting dalam penentu kesehatan. Pemanfaatan pelayanan kesehatan paling erat hubungannya dengan kapan seseorang memerlukan pelayanan kesehatan dan seberapa jauh efektifitas pelayanan tersebut. Penelitian ini bertujuan untuk mengetahui pemanfaatan pelayanan kesehatan oleh masyarakat Kelurahan Rum di wilayah kerja Puskesmas Rum Balibunga Kota Tidore Kepulauan Tahun 2019. Jenis penelitian ini adalah penelitian kualitatif dengan menggunakan pendekatan deskriptif, dengan informan sebanyak 6 informan. Hasil penelitian menunjukan pemanfaatan pelayanan kesehatan oleh masyarakat Kelurahan Rum di Wilayah Kerja Puskesmas Rum Balibunga, meliputi pengetahuan dan persepsi masyarakat akan pelayanan kesehatan sudah baik, perilaku memanfaatkan pengobatan tradisional dibanding pelayanan kesehatan harus di ubah, sikap dan tindakan masyarakat akan pemanfaatan pelayanan kesehatan belum baik, sikap masyarakat biasa saja ketika melihat masyarakat melakukan pengobatan tradisional padahal tindakan petugas kesehatan dalam memberikan pelayanan sudah baik, fasilitas belum lengkap tetapi sudah sesuai standar kesehatan, dimana berpengaruh dan tidak berpengaruh terhadap minat masyarakat untuk berkunjung, petugas kesehatan melakukan kunjungan rumah ke masyarakat. Sosial budaya mempunyai pengaruh dan tidak membatasi minat masyarakat. Bahkan masyarakat tetap percaya dan butuh pelayanan kesehatan, namun ada yang masih melakukan pengobatan tradisional dan berobat ke Dukun. Diharapkan masyarakat agar lebih memanfaatkan pelayanan kesehatan sebelum melakukan pengobatan tradisional. Puskesmas Rum Balibunga dapat meningkatkan pelayanan dan melengkapi fasilitas yang belum tersedia, kegiatan kunjungan rumah atau pemberian pelayanan di luar gedung.

\section{Keyword: Pemanfaatan, Pelayanan Kesehatan, Masyarakat}

\section{PENDAHULUAN}

Kesehatan adalah hak asasi manusia dan sekaligus investasi pembangunan bangsa. Untuk itu diselenggarakan pembangunan kesehatan secara menyeluruh agar terwujud derajat kesehatan yang setinggi-tingginya (Kemenkes RI, 2015). Pembangunan kesehatan bertujuan untuk meningkatkan kesadaran, kemauan, dan kemampuan hidup sehat bagi setiap orang agar terwujud derajat kesehatan masyarakat yang setinggi-tingginya, sebagai investasi bagi pembangunan sumber daya manusia yang 
produktif secara sosial dan ekonomis (Undang-Undang No 36 Tahun 2009). Pusat Kesehatan Masyarakat sebagai salah satu jenis fasilitas pelayanan kesehatan tingkat pertama memiliki peranan penting dalam sistem kesehatan nasional, khususnya sub sistem upaya kesehatan (Kemenkes RI, 2014).

Pemanfaatan pelayanan kesehatan merupakan faktor penting dalam penentu kesehatan, yang memiliki relevansi khusus sebagai masalah kesehatan dan pembangunan masyarakat di negara-negara berpenghasilan rendah. Bahkan, pemanfaatan pelayanan kesehatan telah direkomendasikan oleh World Health Organization (WHO) sebagai konsep kesehatan primer dasar bagi populasi yang paling rentan dan kurang mampu. Dan telah menyarankan bahwa kesehatan harus dapat diakses secara universal tanpa hambatan berdasarkan keterjangkauan, aksesibilitas fisik, atau penerimaan jasa (Bakeera, 2009 dalam Karman, dkk, 2016). Faktor pemungkin (enabling factors) mencakup: ketersediaan sarana dan prasarana atau fasilitas. Faktor penguat (reinforcing factors) mencakup: sikap dan perilaku tokoh masyarakat, tokoh agama, dan petugas kesehatan (Notoatmodjo, 2012).

Berbagai penelitian menunjukkan bahwa persepsi masyarakat tentang kesehatan berhubungan dengan pemanfaatan pelayanan kesehatan $(\rho=0,000)$, persepsi masyarakat tentang kualitas pelayanan tidak berhubungan dengan pemanfaatan pelayanan kesehatan $(\rho=0,213)$, pendapatan keluarga berhubungan dengan pemanfaatan pelayanan kesehatan $(\rho=0,004)$, dan terdapat hubungan tingkat pendidikan dengan pemanfaatan pelayanan kesehatan $(\rho=0,000)$ (Napirah, 2016). Ada banyak faktor yang mempengaruhi perilaku peserta PKH dalam memanfaatkan pelayanan kesehatan, faktor predisposisi meliputi informasi, keyakinan, pengalaman, kebiasaan, nilai budaya, kenyamanan, dan faktor pendorong meliputi dukungan sosial, sarana prasarana, biaya, akses, proses pengambilan keputusan, serta faktor pemungkin seperti sikap dari petugas, peraturan/kebijakan, administrasi penyedia layanan (Marnah, 2016). Ada hubungan antara persepi sakit, pengetahuan dan kepuasan peserta PBI Program JKN dengan pemanfaatan pelayanan kesehatan di Puskesmas Kalongan Kecamatan Ungaran Timur (Agustina, 2019).

Berdasarkan data jumlah kunjungan pasien per Puskesmas pada tahun 2016 sebesar 158.283 kunjungan, tahun 2017 menurun sebesar 136.902 kunjungan, dan tahun 2018 jumlah kunjungan pasien ke Puskesmas mengalami penurunan yang signifikan sebesar 78.814 kunjungan. Ada 9 Puskesmas yang dari tahun ke tahun mengalami penurunan jumlah kunjungan dibanding dengan Puskesmas Rum Balibunga yang dari tahun ke tahun mengalami peningkatan jumlah kunjungan. Berdasarkan data kunjungan Puskesmas Rum Balibunga pada tahun 2016 sebesar 6.456 kunjungan,, tahun 2017 mengalami peningkatan sebesar 7.445 kunjungan, dan tahun 2018 kembali mengalami peningkatan jumlah kunjungan sebesar 7.701 kunjungan. Untuk jumlah kunjungan masyarakat Kelurahan Rum ke Puskesmas Rum Balibunga sendiri sebesar 4.267 kunjungan dimana pada tahun 2016 jumlah kunjungannya sebesar 1.359 pasien dan meningkat pada tahun 2017 sebesar 1.546 pasien, tahun 2018 menurun kembali menjadi 1.362 pasien.

Hal ini yang melatarbelakangi peneliti memilih kelurahan Rum sebagai lokasi penelitian dan kelurahan Rum merupakan kelurahan yang masih memiliki budaya atau tradisi yang masih kental, dimana salah satunya yaitu masih sering kali terlihat masyarakat yang melakukan pengobatan tradisional, berobat ke dukun yang dianggap bisa membantu memberikan penyembuhan dan lainlainnya dibandingkan dengan mereka memanfaatkan pelayanan kesehatan yang tersedia. Untuk itu perlunya dilakukan analisis mengenai pemanfaatan pelayanan puskesmas oleh masyarakat dari segi pengetahuan, persepsi, sikap, tindakan, fasilitas, dan sosial budaya.

Tujuan penelitian yaitu untuk mengetahui pemanfaatan pelayanan kesehatan oleh masyarakat Kelurahan Rum di wilayah kerja Puskesmas Rum Balibunga Kota Tidore Kepulauan Tahun 2019.

\section{Metodologi Penilitian}

Jenis penelitian ini adalah penelitian kualitatif dengan menggunakan pendekatan deskriptif, yang bertujuan untuk memperoleh informasi-informasi mengenai keadaan saat ini dan melihat kaitan antara variabel-variabel yang ada, atau dengan kata lain penelitian ini hanya mendeskripsikan informasi apa adanya sesuai dengan variabel yang diteliti melalui indepth interview (wawancara mendalam), terkait dengan "Analisis Pemanfaatan Pelayanan Kesehatan Masyarakat Kelurahan Rum Di Wilayah Kerja Puskesmas Rum Balibunga Kota Tidore Kepulauan Tahun 2019" yang dilihat dari 
pengetahuan, persepsi, sikap, tindakan, fasilitas, serta sosial budaya. Penelitian dilaksanakan pada bulan Juli 2019 di Kelurahan Rum Kecamatan Tidore Utara, yang merupakan wilayah kerja Puskesmas Rum Balibunga.

Informan dalam penelitian ini adalah Kepala Kelurahan Rum serta beberapa orang masyarakat. Informan kunci adalah salah satu petugas kesehatan Puskesmas Rum Balibunga yang dapat memberikan informasi atau gambaran terkait objek penelitian. Adapun cara penentuan informan ataupun informan kunci diambil secara Purposive Sampling dengan kriteria bersedia di wawancarai dan mampu memberikan informasi yang dibutuhkan. Data ini diperoleh melalui wawancara mendalam (indepth Intreview) terhadap informan dengan menggunakan pedoman wawancara serta alat bantu (alat tulis, alat rekam, kamera). Data sekunder diperoleh dari Dinas Kesehatan Kota Tidore Kepulauan, Puskesmas Rum Balibunga Kecamatan Tidore Utara dan Kantor Kelurahan Rum.

Data yang diperoleh dari hasil wawancara mendalam (indepth interview) diolah secara manual dengan mengelompokkan hasil wawancara sesuai dengan tujuan penelitian. Analisis data dilakukan dengan analisis isi (content analysis), kemudian diinterpretasikan data tersebut dan disajikan dalam bentuk narasi. Teknik yang digunakan untuk mengecek kebenaran data yang telah diambil disebut triangulasi. Di dalam triangulasi terdapat tiga macam yaitu dengan triangulasi sumber, triangulasi metode, dan triangulasi data atau analisis. Pada penelitian ini dari ketiga macam triangulasi tersebut, peneliti menggunakan dua triangulasi yaitu triangulasi metode dan triangulasi sumber.

\section{Hasil dan Pembahasan}

Berdasarkan hasil wawancara yang dilakukan oleh peneliti didapatkan bahwa umur informan berkisar antara 26-55 tahun, dengan tingkat pendidikan yaitu 1 informan berpendidikan D-III Kebidanan, 1 informan S1 Ekonomi, 1 informan S1 Guru, 1 informan D-III Keperawatan dan 2 Informan dengan pendidikan akhir SMA. Penelitian dilakukan untuk memperoleh informasi secara mendalam mengenai bagaimana pemanfaatan pelayanan kesehatan oleh masyarakat Kelurahan Rum di Wilayah Kerja Puskesmas Rum Balibunga Kota Tidore Kepulauan Tahun 2019. Untuk mengetahui pemanfaatan pelayanan kesehatan oleh masyarakat Kelurahan Rum di Wilayah Kerja Puskesmas Rum Balibunga dapat dilihat dari hasil wawancara.

\section{Pengetahuan}

Hasil wawancara diperoleh pengetahuan masyarakat tentang definisi pelayanan kesehatan, jenis-jenis pelayanan kesehatan, fungsi pelayanan kesehatan, tujuan pelayanan kesehatann dan syarat pokok pelayanan kesehatan. Masyarakat sudah mengetahui jenis-jenis pelayanan kesehatan, yang terdiri dari pelayanan kedokteran, pelayanan kesehatan masyarakat, dan ada juga yang mengatakan pelayanan kesehatan perorangan atau keluarga. Namun mereka belum menyebutkan jenis pelayanan kesehatan lainnya atau upaya pelayanan kesehatan, yaitu pelayanan kesehatan primer, sekunder, dan tersier. Selain itu sudah tahu fungsi pelayanan kesehatan namun belum terlalu sesuai dengan fungsi dari pelayanan kesehatan yang sebenarnya, salah satu informan menyebutkan salah satu fungsi dari pelayanan kesehatan yaitu untuk menyediakan atau memberikan pelayanan kesehatan ke masyarakat. Informan mengetahui tujuan dari adanya pelayanan kesehatan bagi masyarakat, yaitu mengobatii (kuratif), mencegah (preventif), promotif, menyembuhkan atau memulihkan (rehabilitatif). Pengetahuan tentang syarat pokok pelayanan kesehatan belum menyatakan syaratnya semuanya, dimana hanya menyebutkan syarat pokok yang harus dimiliki oleh pelayanan kesehatan yaitu diantaranya mudah dicapai, mudah dijangkau, bermutu, dan dapat diterima.

“...Menurut saya pelayanan kesehatan itu adalah tempat atau sarana atau suatu upaya yang dilaksanakan secara bersamaan dalam hal mengobati, memulihkan, mencegah dan menyembuhkan sakit baik perorangan atau diri sendiri, keluarga, dan masyarakat secara keseluruhan..." (Wawancara SI, 1107-2019 dan RI, 12-07-2019)

“...Pelayanan kesehatan itu berjenis 3, ada 3 itu pelayanan masyarakat, pelayanan dokter, dan pelayanan kekeluargaan..." (Wawancara EF, 15-07-2019)

"...Kalo dilihat dari sisi pelayanan kesehatan itu kan fungsi pelayanan dan kesehatan itu kan adalah usaha atau upaya untuk mengatur dan mengelola serta memberi pengobatan dan pelayanan pada seluruh masyarakat, jadi tong masyarakat ini petugas kesehatan itu dong berupaya kalo sakit dong harus mengusahakan pengobatan dan memberikan pelayanan yang baik pe tong masyarakat ini..." (Wawancara EF, 15-07-2019) 
“...Preventif, promotif, kuratif dan rehabilitatif..." (Wawancara SI, 11-07-2019)

"...Syaratnya itu pelayanan kesehatan harus jaraknya dekat yang mudah dijangkau oleh tong masyarakat, harus bermutu juga, dan mudah dicapai dari segi ekonomi masyarakat..." (Wawancara EF, 15-07-2019)

Penelitian ini sejalan dengan penelitian yang menyebutkan bahwa semakin tahu responden dengan pelayanan kesehatan itu, maka responden tersebut mampu menentukan respon/sikap (Marnah, 2016). Pengetahuan mendasari seseorang untuk melakukan tindakan pemanfaatan pelayanan kesehatan. Seseorang yang mengetahui pelayanan kesehatan maternal akan melakukan pemanfaatan pelayanan secara optimal (Ulfa, 2017). Pengetahuan adalah hasil penginderaan manusia, atau hasil tahu seseorang terhadap objek melalui indera yang dimilikinya (mata, hidung, telinga, dan sebagainya). Dengan sendirinya, pada waktu penginderaan sampai menghasilkan pengetahuan tersebut sangat dipengaruhi oleh intensitas perhatian dan persepsi terhadap objek. Sebagian besar pengetahuan seseorang diperoleh melalui indera pendengaran (telinga), dan indera penglihatan (mata) (Notoatmodjo, 2010).

\section{Persepsi}

Berdasarkan hasil wawancara, pelayanan kesehatan di puskesmas Rum Balibunga sudah baik, fasilitas tersedia walaupun belum memadai, pelayanan kesehatan perlu ditingkatkan lagi, perilaku masyarakat yang mengutamakan pengobatan tradisional dibandingkan berkunjung ke pelayanan kesehatan harus diubah. masyarakat yang memanfaatkan pelayanan kesehatan di Puskesmas Rum Balibunga itu masyarakat yang tahu betul jika sakit berobat ke pelayanan kesehatan sementara masyarakat yang melakukan pengobatan tradisional itu masyarakat yang memilih berobat tradisional atau memilih pengobatan dari dukun atau obat-obat kampung.

“...Pelayanannya baik menurut saya, alasan saya mengatakan itu karna memang betul pelayanannya sangat baik karna disetiap masyarakat ke Puskesmas Rum Balibunga selalu dilayani dengan baik...Iya saya pernah ke Puskesmas Rum Balibunga jadi saya merasakannya sendiri walau hanya setiap kalo rasa badan tidak sehat atau sakit..." (Wawancara SI, 11-07-2019)

“...Nah kalo fasilitas di Puskesmas Rum Balibunga itu so tersedia tapi mungkin ada beberapa fasilitas yang belom ada..." (Wawancara RI, 12-07-2019)

“...Fasilitasnya belum tersedia semuanya itu setahu saya, namun walaupun begitu kesehatan itu nomor 1 jadi kalo mau sehat ya torang tra perlu tunggu fasilitas itu samua tersedia dulu baru berobat to,jadi biar fasilitas masih seadanya torang wajib datang berobat supaya dapat pengobatan dengan cepat..." (Wawancara EF, 15-07-2019)

“...Fasilitasnya belum sepenuhnya tersedia, ada namun walaupun bagitu fasilitas yang ada sekarang juga sudah dapat mendukung pelayanan di Puskesmas rumbal. Kalo anda bertanya mengenai fasilitas apa yang belum salah satunya yaitu belum ada polik gigi..." (Wawancara WIJ, 18-07-2019)

"...Walaupun pelayanannya saya rasa sudah baik namun menurut saya perlu ditingkatkan lagi agar masyarakat semakin nyaman untuk berkunjung ke Puskesmas Rum Balibunga..." (Wawancara WIJ, 18-07-2019)

"...Kalo bertanya pandangan saya mengenai hal itu tadi, saya rasa masyarakat pe pemikiran itu harus torang ubah sama-sama, kalo bisa torang bersama-sama dengan masyarakat memberikan promosi/penyuluhan kepada masyarakat bahwa pelayanan kesehatan itu penting, jadi sebelum melakukan pengobatan tradisional terlebih dahulu torang berobat di pelayanan kesehatan dulu..."(Wawancara EF, 15-07-2019)

“...Masyarakat yang berobat di Puskesmas Rum Balibunga itu menurut saya masyarakat yang dorang mangarti kalo sakit itu pi berobat di Puskesmas bukan di tempat lain, nanti masyarakat yang pi berobat tradisional itu masyarakat yang berobat di orang tua-tua yang dong minta aer deng ada yang minum obat-obat kampung bagitu..." (Wawancara SR, 09-07-2019)

"...Dari apa yang torang liat dan torang ketahui sendiri masyarakat yang pengobatan tradisional itu yang berobat kampung, sementara yang memanfaatkan pelayanan kesehatan berarti masyarakat yang berobat di Puskesmas atau Rumah Sakit karna yang menurut mereka itu kalo dalam keadaan sakit berobat dulu ke Puskesmas..." (Wawancara EF, 15-07-2019)

Penelitian ini sejalan dengan penelitian yang menyatakan hal ini berkaitan dengan perceived barrier (hambatan yang dirasakan) dimana perubahan perilaku bukan sesuatu yang dapat terjadi dengan mudah bagi kebanyakan orang. Persepsi masyarakat tentang kesehatan sudah sesuai dengan 
konsep sehat-sakit yang sebenarnya, tetapi masyarakat belum melakukan kunjungan ke Puskesmas dalam rangka mendapatkan pelayanan kesehatan. Beberapa individu lebih memilih melakukan pengobatan sendiri ataupun mencari pengobatan yang dianggap lebih baik daripada harus berkunjung ke Puskesmas. (Napirah, 2016). Pengetahuan baik sebagian besar dari kelompok ini memanfaatkan pelayanan kesehatan di puskesmas, karena dengan bekal pengetahuan yang baik mereka sadar akan pentingnya kesehatan bagi kelangsungan kehidupan mereka sendiri. Perubahan perilaku kesehatan melalui cara pendidikan atau promosi kesehatan diawali dengan cara pemberian informasi-informasi kesehatan. Dengan memberikan informasi-informasi tentang cara-cara mencapai hidup sehat, cara pemeliharaan kesehatan, cara menghindari penyakit, dan sebagainya akan meningkatkan pengetahuan masyarakat tentang hal tersebut (Mahfudz, 2018). Persepsi adalah suatu proses otomatis yang terjadi dengan sangat cepat dan kadang tidak kita sadari, di mana kita dapat mengenali stimulus yang kita terima. Persepsi yang kita miliki ini dapat mempengaruhi tindakan kita. Robbin (2003) mendefinisikan persepsi sebagai proses di mana seseorang mengorganisirkan dan menginterprestasikan sensasi yang dirasakan dengan tujuan untuk memberi makna terhadap lingkungannya (Notoatmodjo, 2010).

\section{Sikap}

Untuk mengetahui pemanfaatan pelayanan kesehatan oleh masyarakat Kelurahan Rum di wilayah kerja Puskesmas Rum Balibunga ditinjau sikap meliputi kunjungan ke puskesmas, sikap petugas kesehatan terhadap masyarakat yang ketika sakit tidak ingin berobat ke pelayanan kesehatan, sikap ketika melihat keluarga atau masyarakat lebih memilih melakukan pengobatan tradisional dibandingkan berkunjung ke pelayanan kesehatan, sikap masyarakat yang sulit mengambil keputusan berobat atau tidak ke pelayanan kesehatan, sikap ingin-tidak ingin, senang-tidak senang, dan baiktidak baik yang dimiliki masyarakat tidak mengganggu masyarakat lain.

"...Kalo saya tetap pigi, karna masalah disini tong pe kesehatan jadi kalo biar dia pe fasilitas belum samua ada, tetap dong masih bisa kase pengobatan pe torang..." (Wawancara SN, 06-07-2019)

“...Ooo pasti dapa kase nasihat, tong masyarakat ini jang bikin kalakuan bagitu, me kalo tong sakit berarti pigi berobat la sembuh, jadi pasti kalo dong Puskesmas bawa dapa tau kalo ada masyarakat yang bagitu dong akan tegur deng kase nasehat..." (Wawancara SN, 06-07-2019)

"...Sikap saya sebagai petugas kesehatan jika melihat masyarakat yang seperti itu saya akan menegurnya dan memberikan sedikit nasihat kepadanya..." (Wawancara WIJ, 18-07-2019)

"...Menurut saya biasa, karna saya tau budaya di kota Tidore ini masih begitu kental apalagi mengenai pengobatan tradisional begitu, itu pasti saja ada yang melakukan karna torang ini selain berobat di Puskesmas ada juga yang labe pilih minum-minum obat kampung saja daripada pigi berobat, tapi itu juga kase kembali pe dorang pe diri masing-masing, kalo dong bapikir demi dong pe kesehatan pasti dong akan labe pilih pigi berobat di Puskesmas dulu baru berobat tradisional..." (Wawancara SR, 09-07-2019 dan SI, 11-07-2019)

Hasil wawancara diperoleh sikap biasa saja ketika melihat keluarga atau masyarakat lebih memilih pengobatan tradisional daripada berkunjung ke pelayanan kesehatan, karena menurut mereka budaya di Tidore itu masih kental jadi masih saja ada masyarakat yang melakukan pengobatan tradisional, namun menurut mereka juga bahwa ada alasan mereka melakukan itu dimana karena kemungkinan masyarakat tersebut sudah berkunjung dan memeriksakan diri mereka ke pelayanan kesehatan, akan tetapi hasil yang keluar atau pernyataan dari Dokter, Bidan, Perawat atau tenaga kesehatan lainnya mengatakan bahwa mereka tidak sakit apa-apa, mungkin itu yang menyebabkan mereka memilih berobat tradisional. Selain itu, lingkungan masyarakat ada sebagian masyarakat sulit memutuskan untuk berobat atau tidak ke pelayanan kesehatan, penyebab mereka atau masyarakat sulit untuk memutuskan sebenarnya tidak ada sama sekali, mereka hanya malas atau tidak mau pergi berobat ke pelayanan kesehatan.

"...Masyarakat ini kong bilang sulit putuskan deng, masyarakat ini cuman pamalas pi berobat saja, saya bilang begini karna so banyak yang terjadi. So tau sakit dong tara mau pigi berobat, nanti so mulai tambah parah baru dong langsung pigi..." (Wawancara SN, 06-07-2019 dan SR, 09-07-2019)

"...Alasan saya begini, karena mungkin saja salah satunya mereka tidak ingin datang berobat karena takut disuntik, karena memang ada masyarakat yang takut disuntik, lihat jarum suntik saja dorang so lari, hal ini yang banyak saya dapatkan di kelurahan Rum. Atau bisa saja mereka malas untuk 
pergi ke Puskesmas, atau dalam dong bapikir labe bae minum obat kampung daripada harus kabawa di Puskesmas..." (Wawancara WIJ, 18-07-2019)

Hasil wawancara dengan informan tentang sikap ingin-tidak ingin, senang-tidak senang, dan baik-tidak baik yang dimiliki masyarakat sangat mempengaruhi keputusan masyarakat dalam memilih suatu hal, cara agar sikap masyarakat yang seperti ingin-tidak ingin dan lain-lain tidak mengganggu masyarakat dalam mengambil keputusan adalah dengan mengubah pola pikir atau sikap yang seperti itu.

“...Mungkin harus diubah dan diperbaiki itu cara yang paling tepat. Karna menurut pendapat saya, jika kita sudah dalam keadaan badan atau kesehatan kita ini terganggu, terus untuk apa kita sulit memilih. Sikap seperti itu sebaiknya diubah, karna mending sehat dan sembuh secepatnya to, daripada berlamaan sakit. Kalo tong pigi berobat ke Puskesmas to supaya tau sakit apa, supaya bisa ambe tindakan bikin apa ka apa bagitu..." (Wawancara SI, 11-07-2019 dan RI, 12-07-2019)

Penelitian ini sejalan dengan penelitian yang menyebutkan sikap dari petugas penyedia layanan kesehatan, baik itu petugas kesehatan medis maupun petugas kesehatan alternatif menjadi penilaian kualitas pelayanan kesehatan oleh responden. Kualitas pelayanan lebih terkait pada ketanggapan petugas memenuhi kebutuhan pasien, kelancaran komunikasi antara petugas dengan pasien, keprihatinan serta keramahtamahan petugas dalam melayani pasien, kerendahan hati dan kesungguhan (Marnah, 2016). Sikap merupakan kesiapan untuk bereaksi terhadap objek di lingkungan tertentu sebagai suatu penghayatan terhadap objek (Notoatmodjo, 2012).

\section{Tindakan}

Hasil wawancara diperoleh bahwa tindakan masyarakat ketika melihat keluarga yang sakit ada yang membawanya ke pelayanan kesehatan dan ada yang tidak perlu membawa jika dalam kondisi penyakit ringan akan membawa keluarga mereka ke Puskesmas jika melihat ada yang dalam keadaan sakit. Berbeda dengan informan lain yang mengatakan bahwa mereka tidak akan membawa keluarga ke Puskesmas jika sakit yang dialami hanya sakit biasa, terkecuali sakit itu harus cepat diobati maka mereka akan membawa ke Puskesmas., tindakan mengajak keluarga untuk berkunjung ke pelayanan kesehatan ketika sakit, frekuensi berkunjung ke pelayanan kesehatan, tindakan petugas kesehatan dalam melayani pasien yang datang berkunjung di Puskesmas Rum Balibunga, tindakan yang harus dilakukan ketika berkunjung namun pelayanan yang diberi kurang nyaman.

"...Kalo bagi Ibu itu tarada. Bukan saya tara mau bawa tapi kalo cuman sakit flu, bersin, baingus apa tong harus bawa pigi berobat ke Puskesmas. Kalo dia pe sakit itu sakit parah atau yang biasa-biasa tapi harus butuh pengobatan cepat ya saya akan bawa keluarga ke Puskesmas atau Rumah Sakit kalo perlu..." (Wawancara RI, 12-07-2019)

"...Sepengetahuan saya kalo kita sakit sebaiknya membawa ke Puskesmas biar itu sakit ringan atau biasa, karena kita tidak tau sakit ringan yang menurut kita itu biasa bisa saja berubah jadi sakit berat, jadi lebih cepat diobati kan lebih baik, jadi kalo saya sih saya akan bawa ke Puskesmas..." (Wawancara EF, 15-07-2019)

"...Kalo yang saya lakukan itu membawa ke pelayanan kesehatan, tapi juga tergantung dari masing-masing orang ya. Karna pendapat masyarakat itu berbeda antara satu dengan yang lain. Dan saya mengatakan bagini karna menurut saya kesehatan itu penting dan menjadi prioritas utama, karna jika dalam keadaan sakit pasti akan menjadi salah satu kendala dalam melakukan aktivitas tiap hari..." (Wawancara WIJ, 18-07-2019)

“...Menurut saya tindakan petugas kesehatan Puskesmas Rum Balibunga ketika melayani pasien atau kita masyarakat ini sangat cepat dan sangat baik, mereka cepat tanggap, ketika masyarakat datang langsung dong layani secepatnya, tra berlama-lama maksudnya tra lelet kerja bagitu, baru saat tongdatang dong langsung berikan pelayanan dengan senyumnya, pas baperiksa dong tanya sakit apa, dibagian mana yang sakit deng lain-lain, jadi menurut saya dia pe tindakan itu capat, dong langsung tanggap..." (Wawancara SI, 11-07-2019 dan RI, 12-07-2019)

“...Harus memperbaikinya, karna tugas petugas itu kan memberikan pelayanan yang baik yang harus bikin masyarakat itu nyaman saat berkunjung atau datang berobat ke Puskesmas, jadi kalo so bagitu dong harus rubah karna tong masyarakat ini datang berobat jadi dong harus layani pe torang deng bikin tong nyaman saat berobat..."(Wawancara SR, 09-07-2019 dan SI, 11-07-2019)

"...Kita harus merubahnya, karena kalo pasien so rasa tra nyaman tong sebagai petugas kesehatan ni tong harus berfikir apa yang bikin sampe pasien itu rasa tra nyaman deng tong pe pelayanan, apa 
karena tong pe muka model deng orang marah-marah, tong tra senyum-senyum atau hal-hal lain yang bikin dong tra nyaman itu apa begitu, jadi menurut saya tindakan yang harus tong lakukan adalah dengan mengubahnya..." (Wawancara WIJ, 18-07-2019)

Penelitian ini sejalan dengan penelitian yang menyebutkan tindakan petugas kesehatan memiliki hubungan bermakna dan dengan Pemanfaatan Pelayanan Kesehatan di Puskesmas, dan yang paling dominan hubungannya adalah persepsi terhadap tindakan petugas kesehatan (Rumengan, 2015). Suatu sikap belum otomatis terwujud dalam suatu tindakan (overt behavior). Untuk mewujudkan sikap menjadi suatu perbuatan nyata diperlukan faktor pendukung atau suatu kondisi yang memungkinkan, antara lain adalah fasilitas. Setelah seseorang mengetahui stimulus atau objek kesehatan, kemudian mengadakan penilaian atau pendapat terhadap apa yang diketahui, proses selanjutnya diharapkan ia akan melaksanakan atau mempraktikkan apa yang diketahui atau disikapinya (dinilai baik). Inilah yang disebut praktik (practice) kesehatan, atau dapat juga dikatakan perilaku kesehatan (overt behavior) (Notoatmodjo, 2012).

\section{Fasilitas}

Untuk mengetahui pemanfaatan pelayanan kesehatan oleh masyarakat Kelurahan Rum di wilayah kerja Puskesmas Rum Balibunga ditinjau dari fasilitas, meliputi kelengkapan fasilitas pelayanan kesehatan di Puskesmas Rum Balibunga, fasilitas kesehatan bisa berpengaruh dan juga tidak terhadap minat masyarakat untuk berkunjung, fasilitas yang sudah tersedia sudah dapat memberikan kenyamanan bagi pasien ketika berkunjung ke Puskesmas Rum Balibunga, fasilitas kesehatan di Puskesmas Rum Balibunga sudah sesuai dengan standat kesehatan, ada kunjungan rumah atau pemberian pelayanan yang dilakukan oleh petugas kesehatan dari Puskesmas Rum Balibunga ketika ada masyarakat yang tidak dapat pergi ke Puskesmas karena tidak bisa berjalan atau penyebab lainnya.

"...Menurut saya fasilitas di Puskesmas Rum Balibunga itu belum lengkap semuanya kayaknya, saya tidak tau fasilitas apa saja tapi menurut saya masih belum ada samua..." (Wawancara SI, 11-072019)

"...Ya pasti karna kalo fasilitas itu bagus maka minat masyarakat datang berobat juga akan semakin banyak..." (Wawancara RI, 12-07-2019)

“...Kalo saya bisa dan juga tidak, Alasannya itu karena menurut pendapat petugas kesehatan dan masyarakat kan berbeda-beda, kalo menurut petugas kesehatan itu berpengaruh sedangkan masyarakat bilang tidak kan tong tra tau, atau sebaliknya..." (Wawancara SI, 11-07-2019 dan EF, 15-07-2019)

Berdasarkan hasil wawancara di peroleh bagus tidaknya serta ada atau tidak adanya fasilitas kesehatan tidak berpengaruh terhadap minat masyarakat untuk berkunjung. Selain itu, ada atau tidaknya dan bagus tidaknya fasilitas kesehatan itu bisa berpengaruh dan juga tidak bisa berpengaruh terhadap minat kunjung masyarakat ke pelayanan kesehatan.

“...Tergantung dari masyarakat masing-masing, kalo saya nyaman-nyaman saja, asal dong layani torang dengan capat saja..." (Wawancara SR, 09-07-2019)

"...Nah kalo bilang bikin nyaman dan fasilitas itu, belum tentu karna pendapat masyarakat ini kan berbeda-beda, ada yang bilang nyaman ada juga yang bilang dong tara nyaman..." (Wawancara RI, 1207-2019)

“...Fasilitas yang tersedia itu sudah sesuai dengan standar kesehatan karna kalo tidak sesuai untuk apa harus digunakan, sesuai jadi mereka selalu gunakan. Memang kalo fasilitasnya masih banyak kekurangan tapi dengan fasilitas yang sudah ada itu menurut saya sudah sesuai dengan standar kesehatan...." (Wawancara EF, 15-07-2019)

"...Saya ada, saya jaga dapa liat dorang dari Puskesmas jaga kunjungi torang masyarakat satu per satu pe rumah, jadi kalo ada masyarakat yang tra bisa bajalang kong tra bisa pigi berobat tu pasti dong akan datang kase pelayanan dirumah saja apalagi kong orang so tua-tua itu dong layani karna dong mangarti usia so tra muda lagi jadi so trada tenaga buat bajalang..." (Wawancara SN, 06-07-2019)

"...Iya kami memiliki kegiatan d luar gedung diantaranya kegiatan PIS-PK, Pembagian Bubuk Abate, Fogging atau pengasapan, penyuluhan dan masih banyak lagi. Serta kami tahu ada masyarakat yang tidak bisa pergi berobat ke pelayanan kesehatan itu kami ketahui ketika turun saat ada kegiatan di luar gedung, dan ada juga laporan dari masyarakat yang mengatakan bahwa ada masyarakat kita yang ingin pergi berobat namun tidak bisa pergi karena tidak bisa bangun dari tempat tidur dan lain-lain..." (Wawancara WIJ, 18-07-2019) 
Penelitian ini sejalan dengan penelitian yang menyebutkan sarana prasarana yang tersedia pada penyedia layanan kesehatan juga menjadi faktor responden dalam memanfaatkan pelayanan kesehatan, seperti penjelasan responden yang melahirkan di puskesmas karena mengetahui sarana yang tersedia cukup lengkap (Marnah, 2016). Terdapat pengaruh positif yang signifikan kualitas pelayanan dan fasilitas kesehatan terhadap kepuasan pasien puskesmas. Hal ini berarti semakin tinggi kualitas pelayanan dan fasilitas kesehatan yang diberikan oleh pihak puskesmas maka akan semakin tinggi kepuasan para pasien yang berobat ke puskesmas (Radito, 2014). Fasilitas pelayanan kesehatan adalah suatu alat dan/atau tempat yang digunakan untuk menyelenggarakan upaya pelayanan kesehatan, baik promotif, preventif, kuratif maupun rehabilitatif yang dilakukan oleh Pemerintah, pemerintah daerah, dan/atau masyarakat (Peraturan Pemerintah Republik Indonesia Nomor 47 Tahun 2016).

\section{Sosial Budaya}

Hasil wawancara pemanfaatan pelayanan kesehatan oleh masyarakat Kelurahan Rum di wilayah kerja Puskesmas Rum Balibunga ditinjau dari sosial budaya, meliputi pengaruh sosial budaya yang ada di masyarakat terhadap pemanfaatan pelayanan kesehatan, kepercayaan masyarakat terhadap pelayanan kesehatan di Puskesmas Rum Balibunga, budaya dan tradisi yang ada di masyarakat dapat membatasi minat masyarakat untuk memanfaatkan pelayanan kesehatan ketika sakit, ketika melihat masyarakat lebih ramai melakukan pengobatan tradisional dibanding berkunjung ke pelayanan kesehatan, apakah pelayanan kesehatan masih dibutuhkan, salah satu budaya atau tradisi masyarakat adalah ketika sakit mereka berobat ke Dukun yang notabennya bukan tenaga kesehatan, hal apa yang menyebabkan mereka lebih memilih berobat ke Dukun dibanding dengan berobat ke pelayanan kesehatan yang tersedia.

“...Dia pe pengaruh tarada sama skali, biar budaya di Tidore kental bagaimana pun kalo yang namanya sakit masyarakat akan berkunjung ke Puskesmas saja, memang ada masyarakat yang pigi berobat ke orang tua-tua, intinya smua dikembalikan ke pola pikir masyarakat masing-masing, tapi menurut saya tara berpengaruh..." (Wawancara RI, 12-07-2019)

"...Bertanya mengenai pengaruh sosial budaya saya rasa tidak dan ada pengaruh, karna walaupun masyarakat selalu memanfaatkan pelayanan kesehatan tetapi tidak menutup kemungkinan mereka juga melakukan pengobatan tradisional..." (Wawancara EF, 15-07-2019)

Hasil wawancara diperoleh bahwa sosial budaya yang ada di masyarakat mempunyai pengaruh dan juga tidak berpengaruh terhadap pemanfaatan pelayanan kesehatan, namun itu juga dikembalikan ke pendapat masing-masing orang.

“...Masyarakat pasti percaya, kalo tarada dong pasti tra akan pigi berobat di Puskesmas. Jadi kepercayaan masyarakat itu beda-beda tapi kalo tanya kepercayaan pe pelayanan di Puskesmas Rum Balibunga itu saya bilang dong percaya,karna kalo tara percaya saya tara akan pi berobat di Puskesmas Rum Balibunga..." (Wawancara SN, 06-07-2019 dan SR, 09-07-2019)

"...Saya menjawab seperti itu karna ini kan berbicara mengenai kesehatan, jadi biar sekental apapun budaya tradisi di Tidore ini tapi kalo demi kesehatan ya untuk memanfaatkan pelayanan kesehatan ketika sakit atau membutuhkan pengobatan ya tidak ada batasan sama sekali..." (Wawancara EF, 15-07-2019)

"...Masih butuhdan butuh sekali, karna biar pengobatan tardisional itu menurut saya cuman jalan pintas pengobatan saja, masyarakat ini masih sangat butuh pelayanan kesehatan..." (Wawancara SR, 0907-2019 dan SI, 11-07-2019)

"...Budaya berobat di dukun ketika sakit itu so jadi hal biasa di kota Tidore khususnya di Rum ini, tapi kalo tanya penyebab berarti itu mungkin saat berobat ke pelayanan kesehatan hasilnya tidak sesuai dengan keadaan yang dialami dia yang merasa bahwa dia sakit, jadi itu mungkin saja yang biking dong berobat di dukun itu, tapi kalo bilang budaya berpengaruh itu tra berpengaruh pe pelayanan kesehatan..." (Wawancara EF, 15-07-2019)

Penilaian ini sejalan dengan penelitian yang menyebutkan semakin mendukung sosial budaya dalam masyarakat tentang pemilihan obat tradisional, maka semakin besar kemungkinan masyarakat untuk memilih obat tradisional, karena kebiasaan dalam masyarakat khususnya kebiasaan yang diturunkan dalam keluarga sangat mudah diterima oleh masyarakat (Ismail, 2015). Faktor lain yang menyebakan keluarga memanfaatkan pelayanan kesehatan tradisional/komplementer adalah faktor kebiasaan dan budaya yang turun temurun dimana kepercayaan terhadap terapi tradisional sudah 
menjadi bagian dari masyarakat Indonesia (Kusumaningrum, 2017). Nilai budaya pada peserta PKH dalam pemanfaatan pelayanan kesehatan sangat erat, seperti ada tradisi masyarakat yang melakukan ritual atau buadaya bepidara, membaca-bacakan doa pada air dan lain sebagainya (Marnah, 2016). Perubahan sosial dan budaya terjadi seiring dengan tekanan besar yang dilakukan manusia terhadap sistem alam sekitar, menghadirkan berbagai macam risiko kesehatan dan kesejahteraan bagi seluruh umat manusia. Tujuan penerapan pelayanan kesehatan modern dan profesional adalah dengan memperhatikan nilai-nilai budaya setempat dan mengadopsi nilai-nilai budaya tersebut dalam upaya beradaptasi dengan budaya masyarakat dalam mencapai tujuan pelayanan kesehatan modem (Isniati, 2012). Seseorang dengan latar belakang budaya yang sama akan menginterprestasikan orang-orang dalam kelompoknya secara berbeda, namun akan mempersepsikan orang-orang diluar kelompoknya sebagai sama saja (Notoatmodjo, 2010).

\section{PENUTUP}

\subsection{Kesimpulan}

Adapun kesimpulan pada penelitian ini adalah sebagai berikut:

1. Pengetahuan masyarakat sudah baik mengenai pelayanan kesehatan, jenis, fungsi, tujuan maupun syarat pokok pelayanan kesehatan.

2. Persepsi masyarakat akan pemanfaatan pelayanan kesehatan sebagai tempat atau sarana berobat sudah baik. Meskipun fasilitas kesehatan di Puskesmas Rum Balibunga belum tersedia secara keseluruhan, masyarakat menganggap pelayanan yang diberikan sudah bagus dan baik. Persepsi perilaku masyarakat yang melakukan pengobatan tradisional dibandingkan ke pelayanan kesehatan harus diubah.

3. Sikap masyarakat akan pemanfaatan pelayanan kesehatan belum baik karena masih ada sebagian masyarakat yang masih tidak memanfaatkan dengan melakukan pengobatan, sehingga sikap atau pikiran demikian harus diubah. Petugas kesehatan sudah baik dalam melayani masyarakat (pasien) atau memberikan pelayanan pada masyarakat yang berkunjung. Pengobatan tradisional yang dilakukan beberapa masyarakat disikapi biasa-biasa saja.

4. Tindakan masyarakat dalam memanfaatkan pelayanan kesehatan belum baik, ada masyarakat yang mengatakan bahwa mereka akan membawa dan mengajak keluarga ke pelayanan kesehatan jika sedang sakit atau sakit parah. Tindakan petugas kesehatan sudah baik dalam memberikan pelayanan kepada pasien (masyarakat) dan apabila jika pelayanan yang diberikan dirasa tidak nyaman maka tindakan yang tepat adalah dengan mengubah atau memperbaikinya.

5. Fasilitas di Puskesmas Rum Balibunga belum lengkap namun sudah sesuai dengan standar kesehatan, dan sebagian masyarakat sudah nyaman dengan fasilitas yang sudah ada dan sebaliknya, serta mempunyai pengaruh/tidak berpengaruh terhadap minat masyarakat untuk berkunjung ke pelayanan kesehatan. Petugas kesehatan melayani pasien (masyarakat) di sarana pelayanan kesehatan, dan melakukan kunjungan rumah dengan memberikan pelayanan kepada masyarakat.

\subsection{Saran}

Diharapkan masyarakat agar lebih memanfaatkan pelayanan kesehatan sebelum melakukan pengobatan tradisional. Puskesmas Rum Balibunga dapat meningkatkan pelayanan dan melengkapi fasilitas yang belum tersedia, kegiatan kunjungan rumah atau pemberian pelayanan di luar gedung.

\section{DAFTAR PUSTAKA}

Agustina, S, Persepsi Sakit, Pengetahuan dan Kepuasan dengan Pemanfaatan Pelayanan Kesehatan di Puskesmas, Higeia Journal Of Public Health Research And Development, Volume 3 Nomor 2 (2019), Hal. 274-285. 
Ismail, 2015, Faktor yang Mempengaruhi Keputusan Masyarakat Memilih Obat Tradisional di Gampong Lam Ujong, Idea Nursing Journal, Volume VI Nomor 1 (2015), hal 7-14.

Isniati, 2012, Kesehatan Modern dengan Nuansa Budaya Kajian Literatur, Jurnal Kesehatan Masyarakat, Volume 7 Nomor 1 (2012), hal 39-44.

Karman., Sakka, Ambo., dan Saptaputra, Syawal., 2016, Faktor-Faktor Yang Berhubungan Dengan Pemanfaatan Pelayanan Kesehatan Bagi Masyarakat Pesisir Di Desa Bungin Permai Kecamatan Tinanggea kabupaten Konawe Selatan Tahun 2016, Fakultas Kesehatan Masyarakat, Universitas Halu Oleo.

Kusumaningrum, A., Hikayati, Lengga, V.M., 2017, Faktor-Faktor Yang Berpengaruh Terhadap Pemanfaatan Pelayanan Kesehatan Tradisional/ Komplementer Pada Keluarga Dengan Penyakit Tidak Menular, Proceeding Seminar Nasional Keperawatan 2017, Volume 3 Nomor 1 (2017), Hal. 254-263.

Mahfudz, A. S., Hayati, R, 2018, Determinan Perilaku Kepala Keluarga Terhadap Pemanfaatan Fasilitas Kesehatan Puskesmas, Jurnal Langsat, Volume 5 Nomor 2 (2018), hal 23-28.

Muslimin, 2015, Perilaku Antropologi Sosial Budaya Dan Kesehatan (Sebuah Pengantar Dalam Perkuliahan), Yogyakarta: Deepublish.

Napirah, M. R., Rahman, A., dan Tony, A., 2016, Faktor- Faktor yang Berhubungan dengan Pemanfaatan Pelayanan Kesehatan di Wilayah Kerja Puskesmas Tambarana Kecamatan Poso Pesisir Utara Kabupaten Poso, Jurnal Pengembangan Kota, Volume 4 No. 1 (2016), hal. 29-39.

Notoatmodjo, S, 2010, Promosi Kesehatan, Teori Dan Aplikasi, Jakarta: PT. Rineka Cipta.

Notoatmodjo, S, 2012, Promosi Kesehatan Dan Perilaku Kesehatan, Jakarta: PT. Rineka Cipta.

Radito, T. A., 2014, Analisis Pengaruh Kualitas Pelayanan dan Fasilitas Kesehatan terhadap Kepuasan Pasien Puskesmas, Jurnal Ilmu Manajemen, Volume 11 Nomor 2 (2014), hal. 1-26.

Rumengan, D.S.S., Umboh, J.M.L., dan Kandon, G.D., 2015, Faktor- Faktor yang Berhubungan dengan Pemanfaatan Pelayanan Kesehatan pada Peserta BPJS Kesehatan di Puskesmas Paniki Bawah Kecamatan Mapanget Kota Manado, JIKMU Suplemen, Volume 5, Nomor 1 (2015), hal. 88-100.

Peraturan Pemerintah Republik Indonesia Nomor 47 Tahun 2016 tentang Fasilitas Pelayanan Kesehatan, 2016, Jakarta: PPRI.

Peraturan Menteri Kesehatan Republik Indonesia Nomor 75 Tahun 2014 tentang Pusat Kesehatan Masyarakat.

Ulfa, Z.D., Kuswardinah, A., dan Mukarromah, S. B., 2017, Faktor-Faktor Yang Mempengaruhi Pemanfaatan Pelayanan Kesehatan Maternal Secara Berkelanjutan, Public Health Perspective Journal, Volume 2 Nomor 2 (2017), Hal. 184-190 